\title{
What has been the impact of the high stakes accountability initiatives on principal and teacher behavior in America?
}

\author{
Kristine Schuler, EdD \\ School of Teaching and Learning, \\ University of Central Missouri \\ Warrensburg, Missouri, USA \\ Barbara N. Martin, EdD \\ School of Professional Education and Leadership \\ University of Central Missouri \\ Warrensburg, Missouri, USA
}

\begin{abstract}
This paper examined the impact high-stakes accountability and data-driven decisionmaking has had on administrators and teacher leaders. The researchers utilized instructional leadership and teacher leadership as conceptual frameworks to explore the participants' perceptions concerning the implementation of national reforms. Selected were four single cases (i.e., individual schools), four principals, as well as 28 teachers to "capture multiple realities" (Creswell, 2009, p. 72) within the data. Through analysis, three themes emerged: 1) Changing Culture; 2) Changing Evidence; and 3) Changing Rigor. These themes provide an understanding of the impact high-stakes accountability has had on public school principals and teachers. Revealed are implications for school districts and leadership/teacher preparatory programs.
\end{abstract}

Keywords: instructional leadership, teacher leadership, high stakes accountability

\section{INTRODUCTION}

National reforms in the USA have changed the standard practices of instructional leaders with an emphasis on federal funding attached to high-stakes testing resulting in both principal and teacher leaders feeling compelled to raise student achievement using any appropriate measures necessary (Bottoms \& Fry, 2009). Challenged with increasing demands for higher student achievement public schools within the United States skills sets needed for educators have been changing (Muhammad, 2015). Similarly, public education has taken on dramatic changes because of federal mandates throughout the last decade. Beginning in January of 2002, the face of the American education system changed with the enactment of the No Child Left Behind Act $(N C L B, 2001)$ and later with the Every Student Succeeds Act (Zinskie, \& Rea, 2016), which mandated public school effectiveness and student proficiency. By placing more emphasis on a standardized curriculum and testing based on the tenets of $N C L B$, national standards began to change and accountability became more rigorous (Standerfer, 2006). As Guthrie and Springer (2004) emphasized, “...the goals of education in the United States have been redefined. The way we measure success has shifted. And the ways we think about improving schools have changed" (p. 24).

Although reform change is not a new challenge to educators, the comprehensive effect of so many policy demands, at such a fast pace led to changes in the educator's role (Muhammad, 2015). Grissom, Nicholson-Crotty, and Harrington (2014) have even highlighted unintended consequences of the myriad of reforms may occur. Accordingly, Owens and Valesky (2011) 
stated, "...efforts to improve the performance of schools have produced not widespread agreement as to how to bring about improvement, but a frustratingly broad array of very different concepts, proposals, and programs, some of which conflict" (p. 5). Bottoms and Fry (2009) further argued reforms have changed the practices of educators due to an emphasis on federal funding attached to high-stakes testing, resulting in both principal and teacher leaders feeling compelled to raise student achievement using any appropriate measures necessary. Because of the high-stakes accountability pressure associated with reform's sanctions, Pedulla, Abrams, Madaus, Russell, Ramos, and Miao (2003) had concerns about how instructional leadership would shift from research-based best practices to one that conforms into a school culture focused solely on achievement scores. These concerns resulted in the following research questions: How has the issue of accountability, as framed by current reforms, affected the role of principals and teachers as instructional leaders? And What, if any, are some of the unintended consequences of high-stakes testing as perceived by principals and teachers?

\section{LITERATURE REVIEW}

As the educational reform initiatives gains more attention, effective leadership holds precedence for improving student achievement (Bottoms \& Fry, 2009). The basis of the theoretical underpinning for this study was the premise that the leader, whether in the role as a principal or a teacher, could continue to influence student performance, which would promote lasting educational change (DuFour \& Marzano, 2009; Firestone, 2009) in a high accountability environment. As a result, two constructs that guided the inquiry were instructional leadership and teacher leadership.

\section{Instructional Leadership}

Although researchers would argue that there are no collective definitions of instructional leadership (Bullard \& Taylor, 1993), all definitions have one common outcome: effective instructional leadership can produce improved academic achievement (Marzano \& Toft, 2014). Found supervising curriculum, gaining resources for improved instruction, and establishing goals through a collective vision, with the intent of improving student learning are instructional leaders (Hallinger \& Wang 2015). While represented in the research are many conceptual frameworks of instructional leadership, Hallinger and Murphy (1985) conceptualization of instructional leadership is the most cited. Viewed through three dimensions: the instructional leadership establishes the school mission and goals with an instructional focus; instructional leadership cultivates an effective instructional program that is supervised, aligned with curriculum, and monitors student progress (Hallinger, 2012), and lastly, instructional leadership encompasses creating a positive school learning ethos.

Midlock (2011) postulated, "Because the main mission of schools focuses on teaching and learning, and because schools' effectiveness often is measured by academic achievement, it is vitally important that the educational leader focus his or her time, energy, and priorities on instructional leadership" (p. 8). Brazer and Bauer (2013) further argued instructional leadership is the determination to improve teaching and learning for students by managing the organization successfully, while supervising teacher learning (p. 650). However as Green (2010) stated, "...during this period of standards-based accountability, instructional leadership has not been elevated to the top of the school leader's agenda" (p. 157).

O'Donnell and White (2005) believed, “...by identifying the strength of the relationships between specific [leader] behaviors and student achievement, educational leaders and politicians will gain a more accurate understanding of the leadership behaviors necessary to improve student performance" (p. 3). Teachers, parents, and students look to the principal for answers when it comes to accountability (Bottoms \& Fry, 2009), viewing the educational 
leaders as directly responsible for the student's performance in their schools. Marshall (2015) illustrated various types of leadership, such as instructional, can yield positive effects on the organizational commitment of teachers. Green (2010) believed, "...leaders are faced with challenges of meeting standards, becoming effective instructional leaders, and assuming responsibility for managing the organization in a manner that facilitates the academic achievement of all students in attendance" (p. 5). Thus, many researchers have argued instructional leadership is assisting educators in meeting the challenges of high-stakes accountability, while noting the role of the instructional leader is changing as a direct result of educational reform (Normore \& Brooks, 2012).

Furthermore, several researchers (Grissom, Nicholson-Crotty, \& Harrington, 2014; Valli \& Buese, 2007) have argued instructional practice has been altered because of high-stakes accountability through focusing on test-taking strategies, and teaching to the test. Thompson (2010) underscored the collection of data, item analysis, and multiple types of instruction happening simultaneously have changed the look of instructional practices and as a result, the role of the principal and teacher as instructional leaders.

\section{Teacher Leadership}

Donaldson et al., (2005) argued, "The urgent need for expertise to expand instructional capacity within schools ( $\mathrm{p}, 1090$ )" has driven the changed focus of teacher leaders. Goddard et al., (2015) noted research on effective teacher development for instructional improvement highlights three characteristics: job-embeddedness, collaboration, and teacher ownership. Similarly, Barth (2001b) suggested "Teachers who assume responsibility for something they care desperately about...stand at the gate of profound learning" (p. 445). To create an environment of improved student achievement, principals and teachers need to work together (Akert \& Martin, 2012). Since it is important to remember that instructional leadership is not solely the responsibility of the principal, teachers must accept an active role if schools are to improve teaching (Akert \& Martin; Hunzicker, 2012). Anderson (2012) similarly argued, "Positioning teachers as leaders can open the possibility for those who are directly affected to have a stake in how changes are envisaged and enacted" (p. 335).

While Wenner and Campbell (2017) noted, "Teacher leadership has of late become an increasingly popular topic among educational policymakers and influential educational organizations as an important component of school reform (p. 135). Although teacher leadership began as a movement concerned with the continuation of the teaching field (Sykes, 1990), it has become closely aligned with instructional leadership focusing on the behaviors of teachers as they engage in activities directly affecting the growth of students ( Hunzicker, 2012; Neumerski, 2012; Sebastian, Allensworth, \& Huang, 2016). Several researchers (Akert \& Martin, 2012; Spillane, Halverson, \& Diamond, 2001) have argued teacher leadership has driven change, as teachers assume both instructional and organizational leadership (Wenner \& Campbell, 2017). Midlock (2011) emphasized since school effectiveness is determined by student achievement it is essential that priority be placed on instruction. Consequently, instructional leadership should be profoundly entrenched not only in the role of the principal (Sergiovanni, 2006) but also the teacher leader (Akert \& Martin, 2012; Anderson, 2012) during high stakes accountability.

There are many benefits to empowering teachers in a leadership role as they have a vital knowledge regarding the daily operations of the school setting while interacting with the clientele (York-Barr \& Duke, 2004). When teachers are involved in decision-making (Louis, Dretzke, \& Wahlstrom, 2010; Louis, Leithwood, et al., 2010), there is higher morale, better decisions concerning students, and ownership in organizational goals (Barth, 2001b). 
Therefore, established is the importance of teachers as leaders, but the unintended consequences of this high stake accountability on teachers' necessities further examination. A myriad of researchers have discovered high-stakes accountability intensified a range of negative outcomes for teachers. These negative outcomes include but are not limited to increased teacher stress (von der Embse, 2017), decreases in motivation (Tadic, Bakker, \& Oerlemans, 2013) and morale (Collie, Shapka, \& Perry, 2012).

\section{Design of Study}

\section{METHODOLOGY}

Through a social constructivist lens, the researchers attempted to understand the multiple realities that existed between the researchers and participants as they pertain to instructional leadership and school reform (Creswell, 2009). Freedman and Combs (1996) noted, "In the social constructivist view, the experience of self exists in the ongoing interchange with others. . . . The self continually creates itself through narratives that include other people who are reciprocally woven into these narratives (p. 17)." This research implemented a qualitative exploratory multi-case study approach. Case study research is particularly relevant when the researcher aims to understand a social phenomenon in context where there is little control over the events (Yin, 2003), and to investigate various viewpoints on the subject of the changing view of instructional leadership due to high stakes accountability reform. By selecting a multi-case study, the researcher intended to provide a "...detailed description of each case and...a thematic analysis across the cases called a cross-case analysis" (Mertens, 2005, p. 75).

\section{Setting}

Site 1: McAllister Elementary School (pseudonym). The first site for this multi-case study was a suburban elementary public school located on the southwest section of the community. This school was a preschool through fifth grade school with a population of more than 400 students.

McAllister Elementary was originally built in 1965 but has received multiple renovations making it a friendly and safe environment. Upon entering the building, visitors were greeted with a door on the left that led to a bright and cheery office. The office staff was very welcoming and helpful. Visitors were asked to sign in and get a visitor's tag. The entryway to the school was decorated with charts and graphs depicting test scores and other data that showed student growth and progress. Once down the hallways of the school, student artwork and science fair projects lined the halls. The hallways were freshly painted and though not new, the building was comfortable and inviting. There were three hallways that were organized by grade levels. Varying degrees of décor in the classrooms were present with kindergarten being more animate than the fifth grade classrooms. Outside, the building was surrounded with playgrounds divided into grade level appropriateness. Each of the playgrounds had an eight-foot fence perimeter.

McAllister Elementary is a Title 1 school that ranks on the upper side of the diversity scale with $51 \%$ of the students being black, $26 \%$ of the students being Hispanic, and $17 \%$ of the students being white. In addition, almost $90 \%$ of the student's population is on free and reduced lunch. According to the Missouri Department of Elementary and Secondary Education, in 2015, McAllister Elementary had an $87 \%$ attendance rate. The faculty at McAllister Elementary boasts an average of 15.8 years of service with $85.7 \%$ of them having a Master's Degree or higher. While disaggregated data shows that McAllister did not meet Average Yearly Progress (AYP) on the MAP test from 2007 to 2011 in either Communication Arts or Mathematics, according to recent data, scores from the Smarter Balanced Assessment ranked from 49\% to $70 \%$ of students earning proficient or higher on the Communication Arts test and 28\% to $49 \%$ earning proficient or higher on the Mathematics test in 2015 (DESE, 2015). 
Site 2: Long Hill Elementary (pseudonym). The next site identified was also a suburban, public, elementary school but it was located in the northern parts of its district. Long Hill Elementary services 490 students in grades kindergarten through fourth. Long Hill Elementary was the newest building of the investigated sites. Opening in 2006, it still had a fresh, clean, modern look to it. The entrance to the building was obvious by the landscaping and benches that greeted visitors. Through the first set of doors there was a security system that needed to be opened by a school secretary. The building appeared extremely secure and the layout was the most advantageous from a security standpoint of the four investigated sites. Once in the doors, students and visitors were greeted with a calming environment. To the left was the office while potted plants, comfy chairs, a large foyer, and the American flag were on display to the right. Throughout the halls, student artwork and classwork lined the walls. As the building was new, the halls were well lit and the decor was up-to-date. The building was arranged in pods with each grade level occupying a designated area. The classrooms were compact but were designed with built in cabinets that complimented the décor.

As Long Hill Elementary was not a Title 1 school, it had the lowest free and reduced lunch rate of $26.2 \%$ of the sites identified in the study. The student population was divided into $74 \%$ white and $14 \%$ black with a high $94 \%$ attendance rate. The Long Hill faculty averaged 10.3 years in the classroom with a surprising $70.8 \%$ of the teachers holding a Master's Degree or higher. The disaggregated data showed that Long Hill students started out strong on the Communication Arts MAP test, meeting AYP 2006 - 2009 though the projected goal was narrowly missed in 2010 and 2011. Yet, students consistently met AYP in mathematics for all years given except one (2009). According to the Smarter Balanced assessment, Communication Arts scores were strong with scores ranging from 59\% to 70\% while Math scores ranged from $56 \%$ to $60 \%$ meeting proficient or better (DESE, 2015).

Site 3: Jackson Elementary (pseudonym). The third site investigated in the study was a suburban, public, elementary school located in the southern part of the district, isolated from the community by a large highway. Jackson Elementary was home to 359 students in kindergarten through fifth grade. Jackson Elementary made it clear that attendance was a building goal. As students and visitors approached the door, there were signs and bulletin boards announcing the importance of coming to school each day. Through the locked doors of the building, there was an office on the left and a small foyer filled with plants, benches and artwork and a large American flag. Though the building was older, fresh paint and carpet made the environment welcoming. The building was had two large hallways on two levels with a smaller hallway off the entry foyer. Classrooms were arranged according to grade level. The classrooms were large with spacy closets to hold resources and supplies. There was artwork and classwork displayed throughout the building.

Like several of the other site, Jackson Elementary was a Title 1 school with $81 \%$ of the students on free and reduced lunch. The student demographics was more evenly distributed than the other sites with $40 \%$ black and 18\% Hispanic and 32\% white. As attendance was a high priority at this school, the attendance rate was high at an average of $91 \%$. The day the researcher was observing, the attendance was $100 \%$. It was the fourteenth time the students had reached this goal during the 2015-2016 school year, were rewarded with a party. The Jackson faculty averaged 13.2 years in the classroom with $50 \%$ of the teachers holding a Master's Degree or higher. The disaggregated data showed that Jackson Elementary students did well in the early years on the Communication Arts MAP test, meeting AYP in 2006, 2008, and 2009 but missing the mark in 2007, 2010, and 2011. Unfortunately, mathematics fared poorly as students only recorded two years having met AYP. According to the Smarter Balanced assessment, Communication Arts scores were consistent with scores ranging from 
$45 \%$ to $67 \%$ while Math scores ranged from $45 \%$ to $56 \%$ meeting proficient or better (DESE, 2015).

Site 4: Oakvale Elementary (pseudonym). The final site identified was also a suburban, public, elementary school, located in the southern parts of its district, again, cut off from the major heart of the district by a large highway. Being the smallest of the schools researched, Oakvale Elementary serviced 317 students in grades kindergarten through fourth.

Not only was Oakvale Elementary the smallest site, it was the oldest site investigated. Yet, the building had old world charm and was well-maintained. The entrance to the building was wide and spacious. It also had secure doors that needed access by a secretary. Through the first set of doors was a security system that needed to be opened by a school secretary. Past the second set of doors, students and visitors were greeted with a calming environment. To the left was the office and to the right was the entrance to the gymnasium flanked by seating and a fountain. Throughout the halls, student artwork and classwork lined the walls. The hallways were a serious of ramps and though very small, there appeared to be ample room. The building had two long hallways that housed the classrooms, media center, and the cafeteria.

Oakvale Elementary was a Title 1 school, yet it only had a free and reduced lunch rate of $37.2 \%$. The student population was the least diverse with $91 \%$ of the students being white. The Oakvale faculty averaged 10.7 years in the classroom and within this study, boasts the highest teacher education rate at $78.3 \%$ of the teachers holding a Master's Degree or higher. According to DESE's data, the attendance rate for Oakvale Elementary students was an impressive $91 \%$. The disaggregated data showed that Oakvale students started out strong on the Communication Arts MAP test, meeting AYP in 2006 - 2008 though the projected goal was missed in 2009 and 2010. Just like Long Hill Elementary, Oakvale students consistently met AYP in mathematics for all years given except one (2009). According to the Smarter Balanced assessment, Communication Arts scores were consistent with scores ranging from $48 \%$ to $66 \%$ while Math scores were lower ranging from $41 \%$ to $45 \%$ meeting proficient or better (DESE, 2015). It should be noted that when the 2009 data was published, Oakvale Elementary was publically shamed during a district-wide assembly for not meeting AYP. The data will identify what types of actions took place in the building as a result of being discredited in this manner.

\section{Participants}

This research attempted to provide purposeful sampling, "...deliberately seeking a variety of opinions on controversial topics and a variety of levels of allegiance to the formal organization" (Mertens, 2005, p. 322). To ensure a purposefully selected population used was a multiple criterion-based sampling method. The first criterion was the school setting. To assure comparable student populations considered were two suburban school districts surrounding one large metropolitan city in one Midwest state. First chosen due to their close approximation to a large metropolitan setting, and then due to their comparable student population regarding ethnic makeup and student population size. Additionally, each of these districts have multiple elementary schools within their boundaries and both have highly qualified staff, with an average tenure of 10 years and the majority of teaching staff have advanced graduate degrees. Finally, both of these districts have achieved accreditation by the Education Department within this Midwest state.

From each of these two school districts, two principals and 14 teachers were purposefully selected because they had been in the education profession for at least ten years (pre and post $N C L B$ and ESSA), and all were viewed as instructional leaders by their superiors. This data 
collection resulted in four principals interviewed, and conducted were four focus groups of teachers ( $\mathrm{N}=7$ teachers from each building).

\section{Data Collection}

The researchers collected data using interviews with principals, focus groups of teachers, and observations to gain deep, meaningful information to answer the questions concerning instructional leadership and mandated high-stakes testing. By accessing these data sources, the researchers produced multiple methods of data collection to strengthen the triangulation of the data (Creswell, 2009; Yin, 2003).

\section{Interview Protocol}

Conducted at each site were interviews with each of the four principals in a one-on-one setting during a day site visit. Using a "structured format" of 10 open-ended and pre-established questions (Creswell, 2009) framed around the elements of instructional leadership, teacher leadership and highs stakes accountability as presented in the literature, this process took approximately 60 minutes to complete (Mertens, 2005, p. 386). While interviewing, the researcher assumed a "middle-ground position" and employed "moderate participation" (Creswell, 2009, p. 139). During the interview and audio recordings, the researcher took extensive field notes. Before recording, the researcher gained permission from the participants including the use of the audio recordings. The use of these recordings reinforced the field notes or "jottings" (Creswell, 2009, p. 138) taken by the researchers and ensure the credibility of the data collected.

\section{Focus Group Protocol}

In addition to the interviews, conducted were focus groups to gain an insight into the teacher's perspective of the issues behind high-stakes accountability and its impact upon their instructional leader and their leadership. Creswell (2009) stated that using focus groups were best when individuals would be hesitant to provide information in a one-on-one setting yet if groups were homogeneous. Four focus groups were consisting of five to seven teachers that fit the qualifications in each group. Mertens (2005) agreed that only a few groups are required when the research was controlled and investigative. There were 5-7 open-ended questions focused on the topic of NCLB and ESSA, high-stakes accountability and instructional leadership. These open-ended questions were aligned to the issues discussed during the interviews with the principals (Krueger \& Casey, 2009). The interviewer looked for verbal and non-verbal cues as well as interactions among the group members (Mertens, 2005).

\section{Observations}

Observation provided additional information benefitting the study. Creswell (2009) noted observations moves the researcher toward greater understanding of the case. Balanced was the interaction between the researcher and the participants: congenial yet non-intrusive. While observing, the researcher looked for any behaviors that showed meaning or were potentially symbolic to the participant (Mertens, 2005). Also, the researcher looked for signs of what was not happening "...especially if it ought to have happened" (Patton, 1980, p. 91). Simple nuances were the main objective as the researcher observed the participants.

\section{Data Analysis}

Conducted via an iterative process was data analysis that identified common themes and triangulated multiple data sources (Huberman \& Miles, 2002). Through a social constructivist lens, the researchers attempted to understand the multiple realities that existed between the researcher and participants as they pertain to instructional leadership, teacher leadership and high stakes accountability because of reforms (Creswell, 2009). As educators, the researchers 
have an interest in understanding the individual stories of the participants and how they connect to the broader school environment (Creswell, 2009), and through these stories, the researcher intended to make sense of the meanings individuals attach to the world around them.

By preparing and organizing the data, finding themes and connections, and compiling the information into meaningful narrative, the researcher analyzed whether reforms affected the role of the instructional leaders (Creswell, 2009). Codes were constructed based on similar word choice, similarities and differences between the interview and the focus groups, and metaphors and analogies (Creswell, 2009; Mertens, 2005). Used were these codes to create a cross-case analysis identifying associations among the variables and finding patterns or themes that made sense of the data (Creswell, 2009). The final step in the analysis process was to present the data, with the choices of "...text, tabular, or figure form...," the researcher presented findings from the interviews, observations, and focus groups in a text form (Creswell, 2009, p. 154).

\section{FINDINGS}

The following themes emerged: 1) Changing Culture, 2) Changing Evidence and 3) Changing Rigor. These themes provide an understanding of the impact high-stakes accountability has had on principals and teachers.

\section{Theme 1: Changing Culture}

Acknowledged most was the impact high-stakes accountability had on collaborative processes of teachers. When discussing collaboration, participants divided the conversation into two separate timelines: partnership prior and after high-stakes accountability. As teachers reminisced, the conversation continually returned to the nature of teamwork before the implementation of testing with sanctions, and teamwork now occurs. In agreement were teachers when one stated, "Prior, you did independent lessons. We did not collaborate" while another admitted there was "...No expectation for collaboration." Administrators concurred with the teachers regarding a lack of focused collaborative planning. One principal stated, "I think we have always known the importance of having teachers being able to team together ...but only on the last few years has the purpose of collaboration changed" The implementation of accountability changed the focus of this collaborative process to become more purposeful. Viewed before the reforms, a teacher recalled, "...here's what I'm doing... other teachers could either take it or leave it." However, since the implementation of the reforms, teachers are working together, using student learning data. One teacher stated, "Even the role of the grade level chair has change, now I must facilitate a meeting that is all data-driven, so that our decisions are more focused." A principal responded, "We now understand that we're all in this together, supporting each other...we're not in our room, closing the door." Still the principals were collectively looking for ways to improve collaboration. As a principal remarked, "I think the number one thing, is just trying to find the support, and not letting teachers feel like they're all by themselves." A teacher emphasized, "If is expected that we work together and that each of us take a lead in making changes in our instruction." There was also agreement regarding the power that intentionality had on collaboration, as one principal noted, "Think about how we can improve lessons....what if we did allow teachers the time to dig deep and think about the intentionality of student learning..." Overall, the data suggests that a changing culture of teachers collaborating with intentionality was a notable improvement due to reform.

\section{Theme 2: Changing Evidence}

Most of the participants viewed analyzing data positively, but some not so, as the catalyst for how one should measure student learning. Although collecting data through the school has 
been happening for years, now used for validating if a student had learned were the data. As a principal noted, "When I think of my job today, I put myself in a situation to always stay on top of learning by not just looking at data but being engrossed in conversations with teachers about what is working and what isn't working for student learning. "Another principal concurred, "It causes us [all] to look at every piece of data. We take a harder look at what we need to change." Many teachers agreed with the changing emphasis on data, as a teacher echoed, "Everything we do, we try to make it data-driven and aligned to instruction." Many teachers noted that their role in data analysis had changed and they now were consider the leaders when discussing what students has learned. As one teacher stated, "I have always been a teacher leader but my role in data analysis has changed with me leading groups of teachers beyond my grade level." Other teachers viewed the process as invasive and counterproductive. A teacher commented, "...we're doing constant data, so much so that there's no time for teaching."

Moreover, another lamented, "We are getting to the point where we do data analysis before a normal kid can have the time actually to make it." Therefore, even though there were some disagreements on the value of data analysis, there was agreement that data is necessary to drive instruction. Also, the majority of teachers seemed to understand the benefits, as one expressed, "Now that we understand the purpose of the data collection, with the focus on student learning, we are seeing the value." As with collaboration, the intentionality makes data analysis work. A principal summed up the change in measuring student learning, "We do a better job now of using formative assessments and lead teachers to guide our instruction towards shorter-term goals ...it's much more useful and because of that we can react much quicker to changing instruction than we could in the past."

\section{Theme 3: Changing Rigor}

The majority of the participants were in agreement concerning the changing rigor and the unintended consequences: aggressive pace and performance, along with stress for teachers. As one of the teachers elucidated, "There initially was a lot of panic." While a principal noted, "It really can be a pressure cooker..." Consequently, all of the participants noted the students were the ones that suffered the most in an environment of aggressive pace. One teacher reported that as a result of accelerated instruction, “...I've seen more anxious[ness] and anxiety in students..." As a teacher commented, "The requirements are so high now; they [students] simply just fell apart..." A principal remarked that under normal circumstances, "Some kids just need the time and we can't always give it to them." While a teacher concurred, "...I think we don't see the child as a whole child...we see them sometimes as a number..." Both principals and teachers agreed though this changing rigor, a climate of uncertainty has led to stress. One principal recalled at one beginning-of-the-year meeting after posting all of the scores for all of the teachers to view. "I was told that it was going to happen and I said, "Don't do it." I said, "No good can come from this," and there were very hard feelings for years..." As the principal went on, "there is danger in penalizing when you should be encouraging." A teacher noted, "I have always been considered a leader in the school but with everything at stake I don't want to be the messenger." While another teacher emphasized, "These reforms have changed how everyone does business in our schools. No longer do we visit among ourselves at meetings, now we are busy trying to show how well our students are doing." Another teacher noted, "I am glad that I am at the end of my career because this accountability rigor could have longterm impact on how long I stay in the classroom."

\section{DISCUSSION}

Delving through the data, it became apparent that both administrators and educators viewed collaboration as divided into a two-part timeline. In 2006, prior to the accountability of NCLB, 
the manner in which teachers and administrators collaborated was superficial at best. The culture was a secluded one and teachers were ultimately on their own when it came to developing curriculum and implementing best practices. There were numerous accounts from the educator participants illustrating how isolation was daunting as they began their careers. Although participants acknowledged that they believed, at the time, they were collaborators, they have only begun to now realize how removed they actually were. The second half of the timeline examined the collaborative framework after 2006 when high-stakes accountability was in full force. Through the perceptions of the participants, this cultural shift led to effective collaboration. It was evident from interviews and focus groups the participants highly regarded the benefits of being part of a collective nature. While each building had its own culture, and each building addressed collaboration in its own way, the conclusion is there is no correct way to collaborate as long as classroom doors metaphorically are opened. The traditional mindset prior to NCLB and ESSA, evolved into teachers working together to combat the intended and unintended consequences of high-stakes accountability. In addition to planning time, being used to analyze student-learning, administrators began to use their teacher as leaders in a more shared leadership routine.

In addition, according to the study findings, aggressive performance expectations were also changing the culture of the school setting. The threat of sanctions and the pace of the instruction, had led to a stressful situation for educators, with many of the administrator participants acknowledging their teachers were overwhelmed with the workload. It was further indicated that teachers were frustrated with the implementation of new initiatives before the previous initiatives were fully implemented and evaluated. The combination of these stressors created the potential for a negative environment. Consequently, as an instructional leader, the administrator has realized one of their major responsibilities was to support the teachers. Since the instructional leader is responsible for the culture and, according to these administrators studied, they must find a way to relieve the stressors resulting from the reform and create supports for their teachers.

Additionally, administrators saw the value of the use of data, even as it transformed their roles because it turned what was once a subjective aspect of the job, student learning, into something that was quantifiable. The administrators within this study agreed that data analysis was quickly becoming a significant part of their jobs. However, the educator participants did not agree as wholeheartedly. Teachers perceived the data as time consuming and believed it distracted them from teaching the whole child. Although participants were of the opinion that data analysis was time consuming, they understood the necessity for the evidence of growth. von der Embse, N. P. (2017) noted there were benefits but raised the question whether it was worth the time taken from direct instruction.

\section{CONCLUSIONS}

Through the data analysis, consensus emerged that the roles for both principals and teacher leaders have changed due to high-stakes accountability. Principals agreed instructional leadership has shifted from a focus on best practices of instruction to an increased focus to facilitate the analysis of data and create collaborative processes for teachers to use the data. Principals also viewed reforms having increased teachers working collaboratively but often with test outcomes being the focus rather than just the aspect of learning. Teachers agreed that their roles had changed as they demonstrate expertise in the use of data to drive instruction, but they did not enjoy the role of leading the process unless every classroom had mastered the standards. They also highlighted the need to have an intentional collaborative process. However as these changes are taking place, all educators' realized one of their major responsibilities is to create a supportive climate that demonstrated a positive ethos. Thus 
according to these educators, they must find ways to relieve the stressors resulting from the reform for everyone involved.

\section{IMPLICATIONS}

One implication would be for teacher preparatory programs, along with teachers in the field, to gain a deeper perspective as to why data analysis is essential and from that, glean how it would benefit them to be leaders in leading the process. Likewise, it is essential for the administrators to understand that adding data analysis to the teachers responsibilities, demands that they provide a myriad of support for the teachers and provide them training, in not only data analysis but also how to be leaders in facilitating other teachers in the process. Principals need to be well versed in understanding how to create time to work together and resources for collaboration to occur. A final implication is addressing the needs of the students and teachers. All four buildings acknowledged that students were anxious and stressed, along with many teachers. With the implementation of high-stakes accountability, the placement of more and more pressure is on the child to perform, along with the classroom teacher. To achieve the achievement results, educators must consider the whole child and provide the necessary supports. Also, the ethos of the school must be on celebrating the milestones of learning in the school, for students along with educators.

\section{References}

Akert, N. \& Martin, B. N. (2012). The role of teacher leaders in school improvement through the perceptions of principals and teachers. International Journal of Education 4(3), http://www.macrothink.org/ije/ DOI: 10.5296/ije.v4i4.2290 p.267-283.

Anderson, M. (2012). The struggle for collective leadership: Thinking and practice in a multi-campus school setting. Educational Management Administration and Leadership, 40, 328-342.

Barth, R. (2001a). Learning by heart. San Francisco, CA: Jossey-Bass

Barth, R. (2001b). Teacher leader. Phi Delta Kappan, 82, 443-449.

Bottoms, G., \& Fry, B. (2009). The district leadership challenge: Empowering principals to improve teaching and learning. Atlanta, GA: Southern Regional Education Board.

Brazer, S. D., and S. C. Bauer. (2013). Preparing instructional leaders: A model. Educational Administration Quarterly 49(4): 645-684

Bullard, P., \& Taylor, B. O. (1993). Making school reform happen. Needle Heights, MA: Allyn \& Bacon.

Collie, R. J., Shapka, J. D., \& Perry, N. E. (2012). School climate and social-emotional learning: Predicting teacher stress, job satisfaction, and teaching efficacy. Journal of Educational Psychology, 104, 1189-1204.

Creswell, J. W. (2009). Qualitative inquire and research design: Choosing among five approaches. Thousand Oaks, CA: Sage Publications.

Donaldson, M. L., Johnson, S. M., Kirkpatrick, C. L., Marinell, W., Steele, J. L., \& Szczesiul, S. A. (2005). Angling for access, bartering for change: How second-stage Teacher Leadership teachers experience differentiated roles in schools. Teachers College Record, 110, 1088-1114.

DuFour, R., \& Marzano, R. (2009). High-leverage strategies for principal leadership. Educational Leadership, $62-68$.

Firestone, W. A. (2009). Accountability nudges districts into changes in cultures. Phi Delta Kappan, 670-676.

Freedman, J., \& Combs, G. (1996). Narrative therapy: The social construction of preferred realities. New York: Norton.

Goddard, R., Goddard, Y., Kim, E.S. and Miller, R. (2015), A theoretical and empirical analysis of the roles of instructional leadership, teacher collaboration, and collective efficacy beliefs in support of student learning, American Journal of Education, 121(4), pp. 501-530.

Green, R. L. (2010). Practicing the art of leadership: A problem-based approach to implementing the ILLLC standards. Upper Saddle River, NJ: Prentice-Hall.

Grissom, J. A., Nicholson-Crotty, S., \& Harrington, J. R. (2014). Estimating the effects of No Child Left Behind on teachers' work environments and job attitudes. Educational Evaluation and Policy Analysis, Retrieved from 
http://www.aera.net/Newsroom/RecentAERAResearch/EstimatingtheEffectsofNoChildLeftBehindonTeachersan dTheirWorkEnvironment/tabid/15549/Default.aspx

Guthrie, J. W., \& Springer, M. G. (2004). A nation at risk revisited: Did 'wrong' reasoning result in 'right' results? At what cost? Peabody Journal of Education, 79(1), 7-35.

Firestone, W. A. (2009). Accountability nudges districts into changes in cultures. Phi Delta Kappan, 670-676.

Freedman, J., \& Combs, G. (1996). Narrative therapy: The social construction of preferred realities. New York: Norton.

Hallinger, P. (2012), A data-driven approach to assess and develop instructional leadership with the PIMRS, in Shen, J. (Ed.), Tools for Improving Principals Work, Peter Lang Publishing, New York, NY, pp. 47-69.

Hallinger, P. and Murphy, J. (1985), Assessing the instructional management behavior of principals, Elementary School Journal, 86(2), pp. 217-247.

Hallinger, P., \& Wang, W. C. (2015). Assessing instructional leadership with the Principal Instructional Management Rating Scale. Dordrecht, Netherlands: Springer.

Hunzicker, J. (2012). Professional development and job-embedded collaboration: How teachers learn to exercise leadership. Professional Development in Education, 38, 267-289. doi:10.1080/19415257.2012.657870

Louis, K. S., Dretzke, B., \& Wahlstrom, K. (2010). How does leadership affect student achievement? Results from a national US survey. School Effectiveness and School Improvement, 21, 315-336.

doi: $10.1080 / 09243453.2010 .486586$

Louis, K. S., Leithwood, K., Wahlstrom, K. L., \& Anderson, S. E. (2010). Learning from leadership project: Investigating the links to improved student learning: Final report of research findings. Retrieved from http://www.wallacefoundation.org/knowledge-center/Documents/Investigatingthe-Links-to-Improved-StudentLearning.pdf

Marshall I. A., (2015) Principal leadership style and teacher commitment among a sample of secondary school teachers in Barbados. Journal of Arts and Humanities 4(5): 43-58.

Marzano, R. J. \& Toth, M. D. (2014). Teaching for rigor: A call for a critical instructional shift. Learning Sciences, West Palm Beach, FL: Marzano Center.

Mertens, D. M. (2005). Research and evaluation in education and psychology: Integrating diversity with quantitative, qualitative, and mixed methods (2nd ed.). Thousand Oaks, CA: Sage Publications.

Midlock, S. F. (2011). Case studies for educational leadership: Solving administrative dilemmas. Upper Saddle River, NJ: Pearson.

Muhammad, A. (2015). Overcoming the achievement gap trap: Liberating mindsets to effect change. Bloomington, IN: Solution Tree Press.

No Child Left Behind Executive Summary (NCLB). (2001). Washington, DC: U.S. Department of Education. Available at: http://nochildleftbehind.gov

Neumerski, C. M. (2012). Rethinking instructional leadership, a review: What do we know about principal, teacher, and coach instructional leadership, and where should we go from here? Educational Administration Quarterly, 49, 310-347. doi:10.1177 /0013161X12456700

O'Donnell, R. J., \& White, G. P. (2005). Within the accountability era: Principals' instructional leadership behaviors and student achievement. NASSP Bulletin, 89(56), 1-17.

Owens, R. G., \& Valesky, T. C. (2011). Organizational behavior in education: Leadership and school reform. Boston, MA: Pearson.

Pedulla, J., Abrams, L., Madaus, G. F., Russell, M., Ramos, M., \& Miao, J. (2003). Perceived effects of state-mandated testing programs on teaching and learning: Findings from a national survey of teachers. Chestnut Hill, MA:

National Board on Educational Testing and Public Policy, Boston College Retrieved from http://www.bc.edu/research/nbetpp/

Rooney, E. (2015). “I'm just going through the motions”: High-stakes accountability and teachers' access to intrinsic rewards. American Journal of Education, 121, 475-500.

Sebastian, J., Allensworth, E., \& Huang, H. (2016). The role of teacher leadership in how principals influence classroom instruction and student learning. American Journal of Education, 123, 69- 108. doi:10.1086/688169 
Sergiovanni, T. J. (2006). Rethinking leadership: A collection of articles (2nd ed.). Thousand Oaks, CA: Corwin Press and National Staff Development Council.

Spillane, J. P., Halverson, R., \& Diamond, J. B. (2001). Investigating school leadership at the elementary, middle, and high school levels. Action in Teacher Education, 19, 49-64.

Standerfer, L. (2006). Before NCLB: The history of ESEA. Principal Leadership, 6(8), 26.

Sykes, G. (1990). Fostering teacher professionalism in schools. In R. F. Elmore (Ed.), Restructuring school: The next generation of educational reform, 55-96. San Francisco, CA: Jossey-Bass.

Tadic, M., Bakker, A. B., \& Oerlemans, W. (2013). Work happiness among teachers: A day reconstruction study on the role of self-concordance. Journal of School Psychology, 51, 735-750.

Valli, L. \& Buese, D. (2007). The changing roles of teachers in an era of high-stakes accountability. American Educational Research Journal, 44(3), 519-558.

von der Embse, N. P. (2017). The psychological and instructional consequences of high-stakes accountability. Psychology of Education Review, 41(1), 45-50.

Wenner, J. A., \& Campbell, T. (2017). The theoretical and empirical basis of teacher leadership: A review of the literature. Review of Educational Research, 87(1), 134-171. DOI: 10.3102/0034654316653478

Yin, R. K. (2003). Case study research: Design and methods London: Sage Publications.

York-Barr, J., \& Duke, K. (2004). What do we know about teacher leadership? Findings from two decades of scholarship. Review of Educational Research, 74(3), 255-316.

Zinskie, C. D., \& Rea, D. W. (2016). The Every Student Succeeds Act (ESSA): What it means for educators of students at risk. National Youth-At-Risk Journal, 2(1).https://doi.org/10.20429/nyarj.2016.020101 